\title{
Genetic effects of heat stress on milk yield of Thai Holstein crossbreds
}

\author{
W. Boonkum, ${ }^{\star} \dagger$ I. Misztal, ${ }^{*}$ M. Duangjinda, $\dagger^{1}$ V. Pattarajinda, $†$ S. Tumwasorn, $\neq$ and J. Sanpote§ \\ *Animal and Dairy Science Department, University of Georgia, Athens 30602 \\ †Department of Animal Science, Faculty of Agriculture, Khon Kaen University, Thailand 40002 \\ ‡Department of Animal Science, Faculty of Agriculture, Kasetsart University, Thailand 10900 \\ §Bureau of Biotechnology in Livestock Production, Department of Livestock Development, Pathumthani, Thailand 12000
}

\begin{abstract}
The threshold for heat stress on milk yield of Holstein crossbreds under climatic conditions in Thailand was investigated, and genetic effects of heat stress on milk yield were estimated. Data included 400,738 test-day milk yield records for the first 3 parities from 25,609 Thai crossbred Holsteins between 1990 and 2008. Mean test-day milk yield ranged from $12.6 \mathrm{~kg}$ for cows with $<87.5 \%$ Holstein genetics to $14.4 \mathrm{~kg}$ for cows with $\geq 93.7 \%$ Holstein genetics. Daily temperature and humidity data from 26 provincial weather stations were used to calculate a temperature-humidity index (THI). Test-day milk yield varied little with THI for first parity except above a THI of 82 for cows with $\geq 93.7 \%$ Holstein genetics. For third parity, test-day milk yield started to decline after a THI of 74 for cows with $\geq 87.5 \%$ Holstein genetics and declined more rapidly after a THI of 82 . A repeatability test-day model with parities as correlated traits was used to estimate heat stress parameters; fixed effects included herd-test month-test year and breed groups, days in milk, calving age, and parity; random effects included 2 additive genetic effects, regular and heat stress, and 2 permanent environment, regular and heat stress. The threshold for effect of heat stress on test-day milk yield was set to a THI of 80. All variance component estimates increased with parity; the largest increases were found for effects associated with heat stress. In particular, genetic variance associated with heat stress quadrupled from first to third parity, whereas permanent environmental variance only doubled. However, permanent environmental variance for heat stress was at least 10 times larger than genetic variance. Genetic correlations among parities for additive effects without heat stress considered ranged from 0.88 to 0.96 . Genetic correlations among parities for additive effects of heat stress ranged from 0.08 to 0.22 , and genetic correlations between effects regular and heat stress effects ranged from -0.21 to
\end{abstract}

Received May 9, 2010.

Accepted August 19, 2010.

${ }^{1}$ Corresponding author: monchai@kku.ac.th
-0.33 for individual parities. Effect of heat stress on Thai Holstein crossbreds increased greatly with parity and was especially large after a THI of 80 for cows with a high percentage of Holstein genetics $(\geq 93.7 \%)$. Individual sensitivity to heat stress was more environmental than genetic for Thai Holstein crossbreds.

Key words: heat stress, milk yield, genetic effect, Thailand

\section{INTRODUCTION}

Heat stress is an important problem for dairy production in many parts of the world because of its negative effects on productivity and profitability (Fuquay, 1981; West, 2003; Bryant et al., 2007). St-Pierre et al. (2003) reported that heat stress greatly affected economic loss by the US dairy industry and that estimated losses ranged from $\$ 897$ to $\$ 1,500$ million annually. Current strategies to reduce the effects of heat stress include adjustment of housing and facilities as well as changes in feed and its management (Armstrong, 1994; West, 1999; Berman, 2008). Although such strategies can be successful in the short-term, they may be inadequate in the long-term if current selection acts against heat tolerance.

Genetic evaluation for heat tolerance could be a sustainable strategy to augment feed or housing modifications. Ravagnolo and Misztal $(2000,2002)$ proposed a method for the study of genetic response under heat stress with models that combined information from public weather stations to predict the impact of climatic change on performance of lactating dairy cows in the United States. The threshold for heat stress was estimated to be a temperature-humidity index (THI) value of 72 for production and around 68 for reproduction. Bohmanova et al. (2005) applied this methodology to analyze first-parity milk yield of US Holsteins. Aguilar et al. (2009) extended that study to include the first 3 parities and found that susceptibility to heat stress increased dramatically from first to third parity, potentially leading to shorter productive life. Although no annual genetic trend for milk yield under heat stress was found for first parity, a negative trend was found for second and third parities (Aguilar et al., 2010). 
Table 1. Data structure for estimation of variance components by parity for Thai Holstein crossbreds

\begin{tabular}{|c|c|c|c|c|}
\hline \multirow[b]{2}{*}{ Category } & \multicolumn{4}{|c|}{ Parity } \\
\hline & 1 & 2 & 3 & All \\
\hline Herd-test month-test year classes, $\mathrm{n}$ & 9,039 & 6,170 & 4,827 & 9,039 \\
\hline Cows, $\mathrm{n}$ & 25,609 & 13,195 & 8,064 & 25,609 \\
\hline \multicolumn{5}{|l|}{ Test-day records, $\mathrm{n}$} \\
\hline$<87.5 \%$ Holstein genetics & 64,550 & 43,194 & 28,024 & 135,768 \\
\hline 87.5 to $93.6 \%$ Holstein genetics & 84,309 & 38,358 & 23,493 & 146,160 \\
\hline$\geq 93.7 \%$ Holstein genetics & 69,224 & 30,930 & 18,656 & 118,810 \\
\hline $\bar{T}$ otal & 218,083 & 112,482 & 70,173 & 400,738 \\
\hline \multicolumn{5}{|l|}{ Mean test-day milk yield $\pm \mathrm{SD}, \mathrm{kg}$} \\
\hline$<87.5 \%$ Holstein genetics & $11.9 \pm 4.4$ & $13.1 \pm 5.1$ & $13.9 \pm 5.5$ & $12.7 \pm 4.9$ \\
\hline 87.5 to $93.6 \%$ Holstein genetics & $12.9 \pm 4.8$ & $14.6 \pm 5.8$ & $15.6 \pm 6.4$ & $13.8 \pm 5.4$ \\
\hline$>93.7 \%$ Holstein genetics & $14.2 \pm 5.5$ & $15.6 \pm 6.5$ & $16.4 \pm 7.0$ & $14.9 \pm 6.1$ \\
\hline \multicolumn{5}{|l|}{ Mean DIM \pm SD, d } \\
\hline$<87.5 \%$ Holstein genetics & $148 \pm 83$ & $144 \pm 82$ & $143 \pm 81$ & $146 \pm 81$ \\
\hline 87.5 to $93.6 \%$ Holstein genetics & $147 \pm 83$ & $147 \pm 83$ & $146 \pm 83$ & $147 \pm 83$ \\
\hline$\geq 93.7 \%$ Holstein genetics & $148 \pm 84$ & $148 \pm 84$ & $147 \pm 84$ & $147 \pm 83$ \\
\hline
\end{tabular}

The former studies involved high-producing purebred herds, which were mostly under intensive management. In tropical countries, many animals are crossbred, production is lower, and heat management is minimal or absent (McDowell, 1985; Madalena et al., 1990). In Thailand, crossbreeding between Bos taurus (Holstein, Jersey, Brown Swiss, and Red Dene) and Bos indicus (Sahiwal, Red Sindhi, Brahman, and Thai Native) has been widely used. However, the major crossbred dairy cattle $(>95 \%)$ was crossbred between Holstein and Sahiwal or Thai Native breeds. The purpose of crossing those 2 breeds was to combine the benefits of improving milk yield from taurine cattle (Bos taurus) and toleration of heat, tick-borne diseases, and other tropical diseases from zebu cattle (Bos indicus; Reodecha, 2002; Chanvijit et al., 2005). Today, Holstein crossbreds with $\geq 75 \%$ Holstein genes are the main population in Thailand (Buaban, 2005). However, breeding to increase Holstein genetics to improve milk yield has been applied without any emphasis on heat stress, and that practice could be contributing to yield losses.

The objective of this study was to investigate heat tolerance and its genetic components for crossbred Holsteins in Thailand. In particular, thresholds for heat stress were examined for crossbreds with different percentages of Holstein genetics, and genetic parameters for effect of heat stress on milk yield were determined for the first 3 parities.

\section{MATERIALS AND METHODS}

\section{Data}

A total of 400,738 test-day records for milk yield for the first 3 parities of 25,609 Thai Holstein crossbreds were obtained from the Department of Livestock Development, Pathumthani, Thailand, and private farms in
26 provinces throughout Thailand from 1990 to 2008. Only records from cows with DIM between 5 and 305 were retained, and cows were required to have records for first-parity milk yield. Calving ages were restricted to 17 to 48 mo for first parity, 27 to 60 mo for second parity, and 34 to 75 mo for third parity. A pedigree file was constructed by tracing back 3 generations of ancestors and included 38,932 individuals. Cows were assigned to 1 of 3 breed groups based on percentage of Holstein genetics: $<87.5 \%, 87.5$ to $93.6 \%$, and $\geq 93.7 \%$. A more detailed description of the data is shown in Table 1.

Climate data were obtained from the meteorological center closest to each dairy farm based on postal code. The weather information included daily temperature and relative humidity recorded every $3 \mathrm{~h}$, which were used to calculate a THI based on the formula used by the National Oceanic and Atmospheric Administration (1976):

$$
\mathrm{THI}=(1.8 \mathrm{~T}+32)-(0.55-0.0055 \mathrm{RH})(1.8 \mathrm{~T}-26),
$$

where $\mathrm{T}$ is temperature in degrees Celsius and $\mathrm{RH}$ is relative humidity as a percentage. Mean daily THI 3 d before each milk test date was used to detect the threshold of heat stress and to estimate genetic parameters as suggested by Bohmanova et al. (2008).

\section{Model}

For genetic analyses, a repeatability test-day model was used with 3 parities considered to be correlated traits as in Aguilar et al. (2009):

$$
\begin{aligned}
& \mathrm{y}_{\mathrm{ijklmn}}=\mathrm{HMY}_{\mathrm{ij}}+\mathrm{DIM}_{\mathrm{k}} \mathrm{BG}_{\mathrm{jl}}+\mathrm{CA}_{\mathrm{jm}}+\mathrm{a}_{\mathrm{jn}} \\
& +\mathrm{\alpha}_{\mathrm{jn}}[\mathrm{f}(\mathrm{THI})]+\mathrm{p}_{\mathrm{jn}}+\pi_{\mathrm{jn}}[\mathrm{f}(\mathrm{THI})]+\mathrm{e}_{\mathrm{ijklmn}},
\end{aligned}
$$



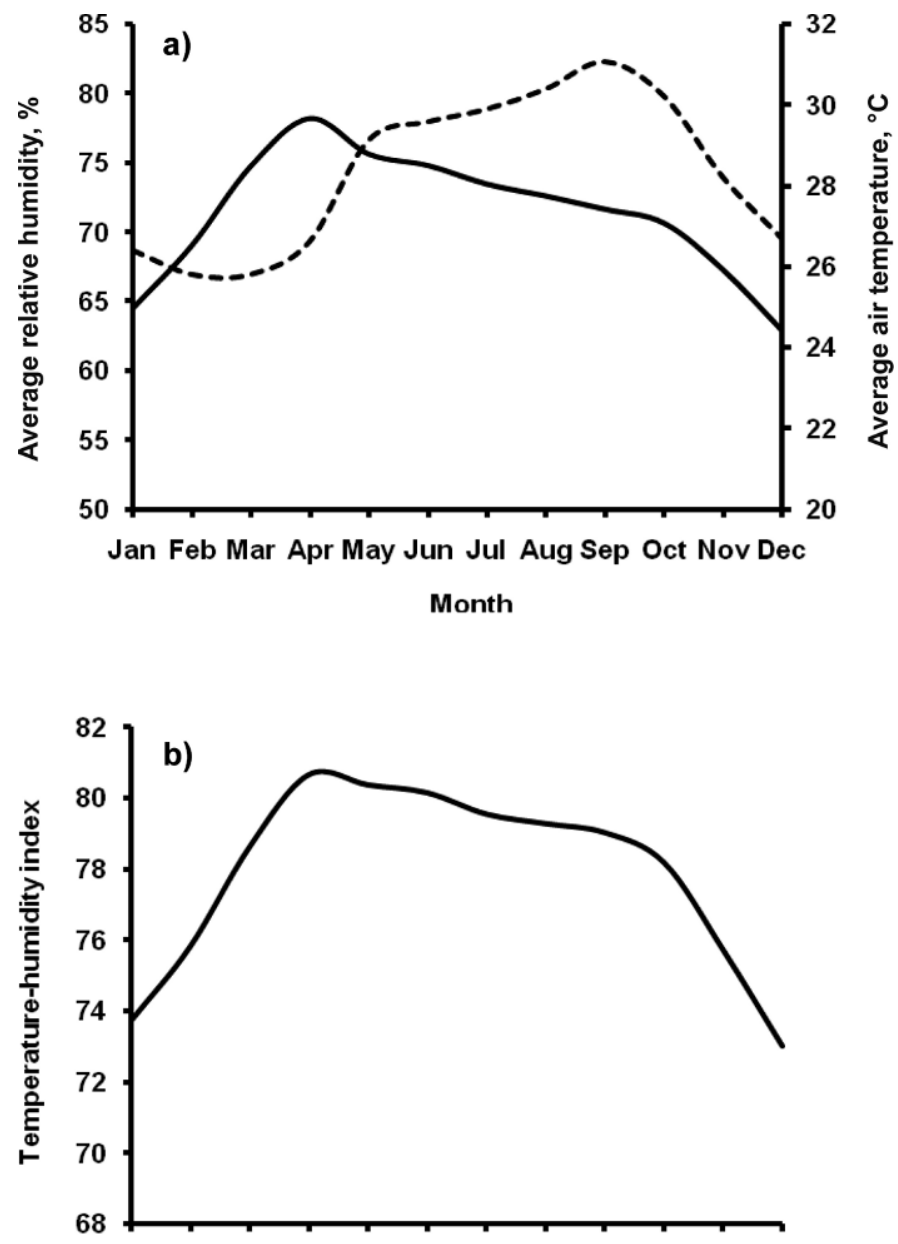

Jan Feb Mar Apr May Jun Jul Aug Sep Oct Nov Dec

Month

Figure 1. Mean a) relative humidity (----), temperature (-), and b) temperature-humidity index in Thailand by calendar month.

where $y_{\mathrm{ijklmn}}$ is test-day milk yield of cow $\mathrm{n}$ in herd-test month-test year (HMY) class i within parity $\mathrm{j}(1,2$, or 3 ), DIM class $\mathrm{k}$ (5 to 34,35 to $64, \ldots, 275$ to 305 DIM) nested within breed group (BG) class $1(<87.5,87.5$ to 93.6, or $\geq 93.7 \%$ Holstein genetics) and parity $\mathrm{j}$, and calving age (CA) class $m$ (CA was grouped every 2 mo for each parity) within parity j; HMY, BG, DIM, and $\mathrm{CA}$ are fixed effects; $\mathrm{a}$ is random additive genetic effect without consideration of heat stress (regular); $\alpha$ is random additive genetic effect of heat stress; $p$ is a random permanent environmental effect without consideration of heat stress (regular); $\pi$ is random permanent environmental effect of heat stress (HS); e is random residual effect; and $\mathrm{f}(\mathrm{THI})$ is a function of THI:

$$
f(T H I)=\left\{\begin{array}{ll}
0 & \text { if THI } \leq \mathrm{THI}_{\text {threshold }}(\text { no HS) } \\
\text { THI }-\mathrm{THI}_{\text {threshold }} & \text { if THI }>\mathrm{THI}_{\text {threshold }}(\mathrm{HS})
\end{array} .\right.
$$

Variance components were estimated with the GIBB2F90 program (Misztal et al., 2002). A single chain of 200,000 samples was run, with the first 20,000 samples discarded as burn-in. Posterior means and standard deviations of parameters were calculated from every 10th sample of 180,000 samples. Convergence was determined based on the effective sample size for each parameter as well as visually by plotting Gibbs samples.

\section{RESULTS AND DISCUSSION}

\section{Climatic Conditions in Thailand}

Climatic conditions of Thailand could be characterized as hot and humid with a mean temperature of $27^{\circ} \mathrm{C}$ and mean relative humidity of $74 \%$. Monthly mean temperatures (Figure 1a) were lowest in December $\left(24^{\circ} \mathrm{C}\right)$ and highest in April $\left(30^{\circ} \mathrm{C}\right)$. Relative humidity (Figure 1a) exceeded $67 \%$ for the entire year. The THI (Figure 1b) was lowest in January and December (mean of 73), which is associated with the winter season, and highest in April through July (mean of 80), which is associated with the summer season. The average test-day milk yield along test month for each of the crosses is shown in Figure 2. In all breed groups, average test-day milk yields were higher in winter than in summer.

\section{Determination of Heat-Stress Threshold}

Figure 3 shows mean test-day milk yield across THI for different breed groups by parity. For first parity, heat stress did not affect mean test-day milk yield for the 2 lower percentage breed groups $(<87.5$ and 87.5 to $93.6 \%$ Holstein genetics), whereas the highest per-

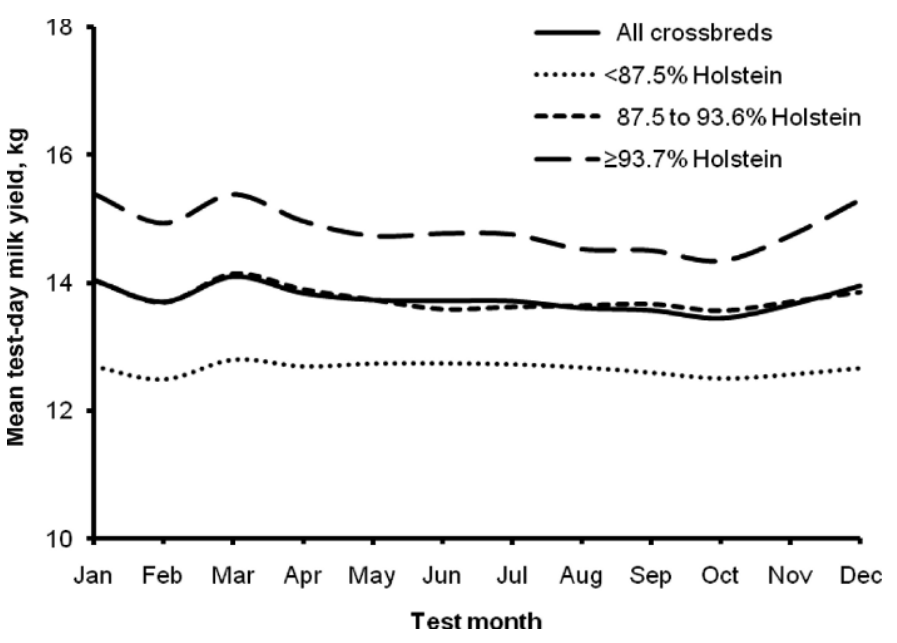

Figure 2. Mean test-day milk yield for all parities across test month separated by breed group based on percentage of Holstein genetics. 
a) Parity 1

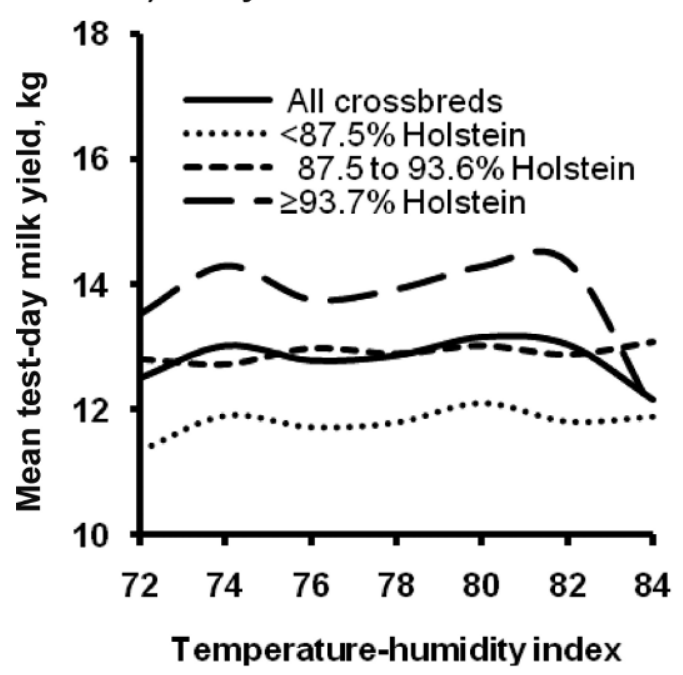

b) Parity 2

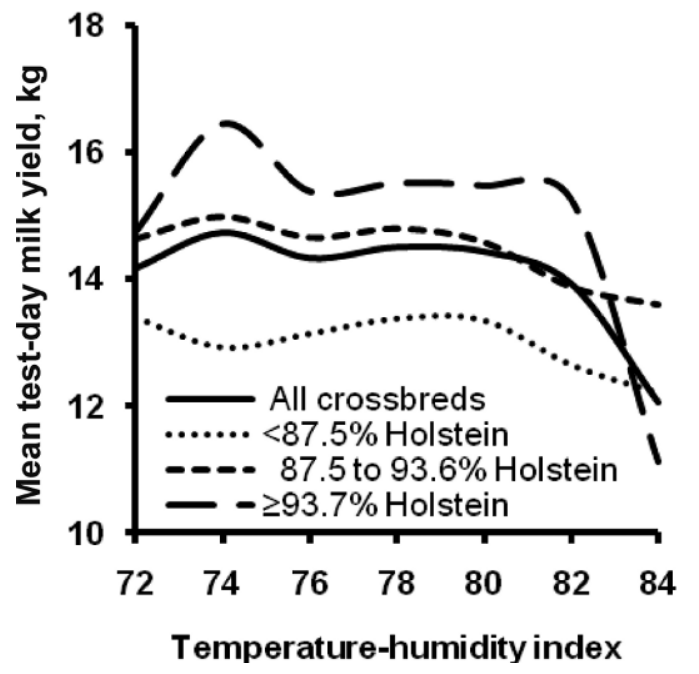

c) Parity 3

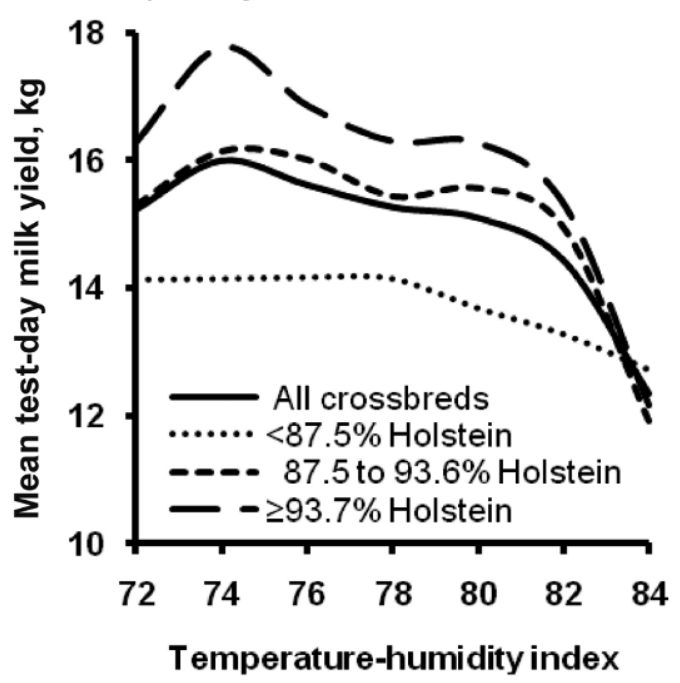

d) All parities

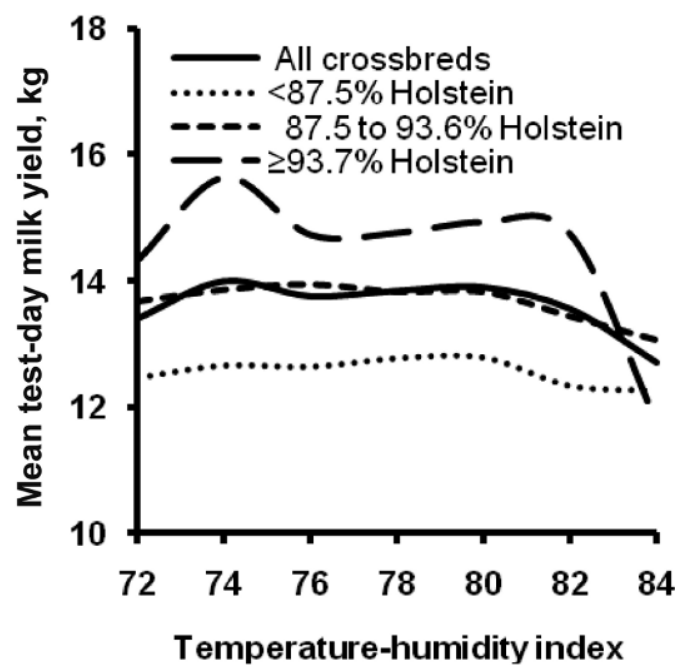

Figure 3. Mean test-day milk yield for Thai Holstein crossbreds across a temperature-humidity index by breed group based on percentage of Holstein genetics for a) parity 1, b) parity 2, c) parity 3, and d) all parities.

centage ( $\geq 93.7 \%)$ breed group had a moderate decline after THI of 74 and a more severe decline after THI of 82. For second-parity animals, the 2 lower percentage breed groups had a slight decline after THI of 80, and the highest percentage breed group had greater declines than for first-parity animals at the same THI thresholds. For third-parity animals, the decline in mean testday milk yield was greater than for previous parities for all breed groups. The decline for the lowest percentage breed group occurred at a THI of 78, whereas declines for the other breed groups occurred at THI of 74 and 80. However, those declines were less for the breed group with 87.5 to $93.6 \%$ Holstein genetics than for the group with $\geq 93.7 \%$, probably because of robustness to heat stress resulting from a larger percentage of genetics from tropical breeds.

Across parities (Figure 3d), a moderate decline in test-day milk yield began around a THI of 80 for the 2 lower percentage breed groups. The threshold for heat stress for the highest percentage breed group was a THI of 82 followed by a sharp decline in yield. However, the declining of test-day milk yield across all crossbreds and parities was found at a THI of 80 . Therefore, the analyses assumed a THI threshold of 80 to represent the threshold for heat stress for the whole population. The THI threshold of 80 is higher than the thresholds of 72 to 76 reported for US Holsteins (Ravagnolo et al., 2000; Freitas et al., 2006a,b; Aguilar et al., 2009). Gen- 
Table 2. Variance component estimates and genetic and permanent environmental correlations among and across parities for test-day milk yield at a temperature-humidity index (THI) threshold of 80

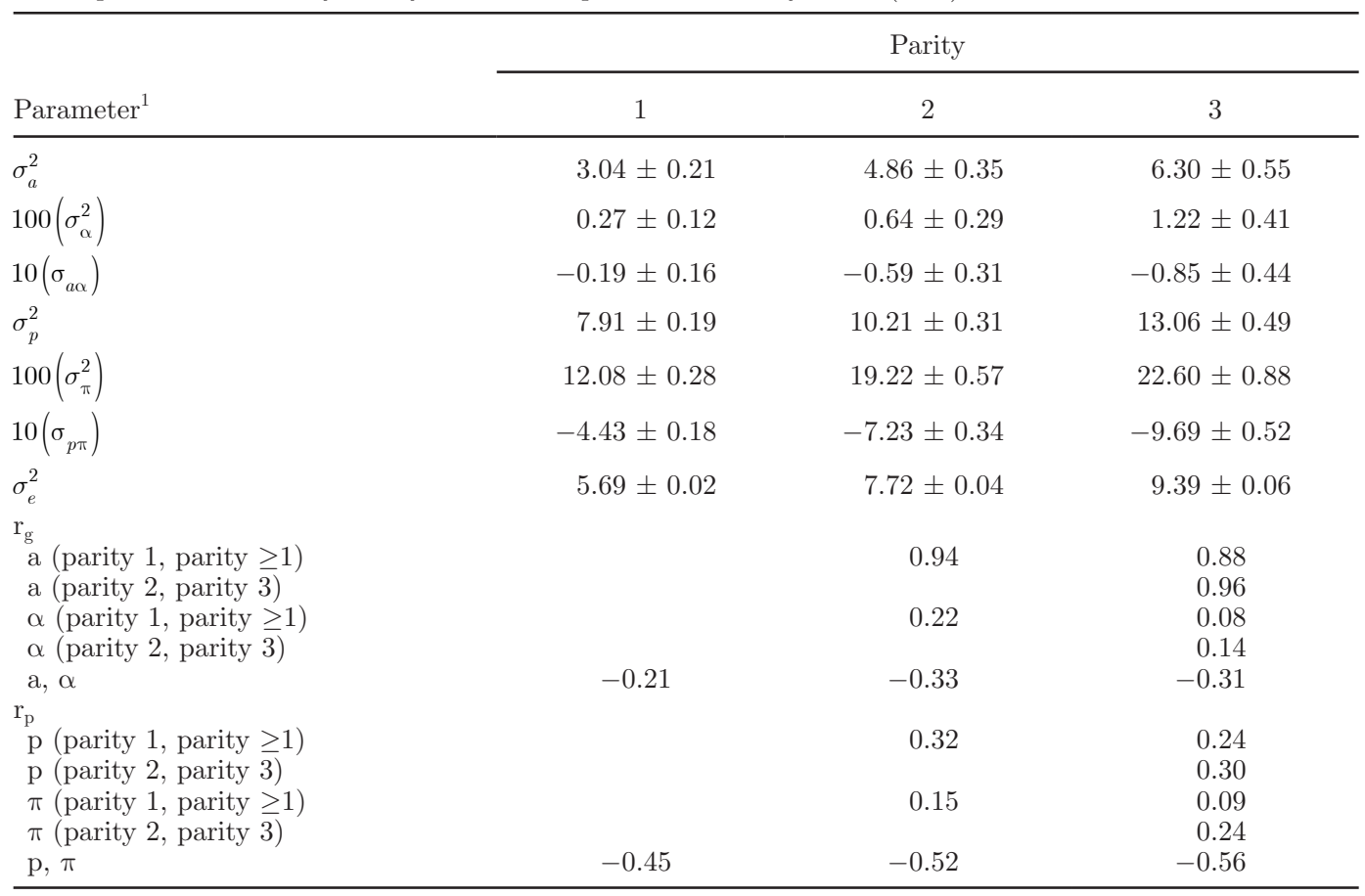

${ }^{1}$ Random additive genetic effects for regular and heat stress are denoted by a and $\alpha$, respectively; permanent environmental effects for regular and heat stress are denoted by $\mathrm{p}$ and $\pi$, respectively; $\sigma_{a}^{2}=$ additive genetic variance without consideration of heat stress; $100\left(\sigma_{\alpha}^{2}\right)=$ additive genetic variance for heat stress at a THI of $90\left(10^{\circ} \mathrm{C}\right.$ over a THI threshold of 80$) ; 10\left(\sigma_{a \alpha}\right)=$ additive genetic covariance between effects with and without heat stress considered; $\sigma_{p}^{2}=$ permanent environmental variance without consideration of heat stress; $100\left(\sigma_{\pi}^{2}\right)$ $=$ permanent environmental variance for heat stress at THI of $90 ; 10\left(\sigma_{p \pi}\right)=$ permanent environmental covariance between effects with and without heat stress considered; $\sigma_{e}^{2}=$ residual variance; $\mathrm{r}_{\mathrm{g}}=$ genetic correlation; and $\mathrm{r}_{\mathrm{p}}=$ permanent environmental correlation.

erally, the lack of cooling devices is expected to lower the threshold for heat stress. As the result, the higher threshold in the Thai crossbred population might due to the combinations of heat-tolerance genes from $B$. indicus and the lower production. Generally, Thai cattle are rarely fed to their genetic potential because of the low quality of tropical roughages.

\section{Genetic Estimates}

Variance components for milk yield at a THI of 80 estimated from simultaneous analysis of the first 3 parities are shown in Table 2. Compared with estimates by Aguilar et al. (2009) for US Holsteins in Georgia, estimates of additive variance without consideration of heat stress were $46 \%$ lower for first parity, $35 \%$ lower for second parity, and almost the same for third parity. However, the corresponding estimates for heat additive variance were at least 7 times lower than those of Aguilar et al. (2009). Even though the estimate of heat additive variance for third parity was more than 4 times greater than for first parity, Thai Holstein crossbreds appeared to have little genetic variability related to heat stress.

Although genetic correlations among parities (Table 2 ) were $\geq 0.88$ for test-day milk yield without consideration of heat stress, they were $\leq 0.22$ when heat stress was considered. Aguilar et al. (2009) reported corresponding genetic correlations among parities of $\geq 0.72$ for heat tolerance. Low genetic correlations among parities indicate that either factors affecting the genetics of heat stress are different for each parity or the effect of heat stress is confounded with other factors.

\section{Permanent Environment Estimates}

Estimates for variance components of permanent environmental effects were higher than those for genetic effects (Table 2). Although estimates without heat stress considered were about 2 times higher, estimates for heat stress were 20 (first parity) to 8 times (third parity) higher. The larger estimates for permanent 
environment effects indicate that sensitivity to heat stress is cow-specific and mostly acquired rather than genetic.

Permanent environmental correlations among parities (Table 2) ranged from 0.24 to 0.32 without heat stress considered and from 0.09 to 0.24 for heat stress. The correlations indicate that environment sensitivity is parity-specific for Thai Holstein crossbreds. The effect for heat stress may also be accounting for effects not associated with heat stress (e.g., seasonal forage quality).

\section{Correlations Between Effects With and Without Heat Stress Considered}

Correlations between additive effects with and without heat stress considered (Table 2) were negative for all parities and ranged from -0.21 to -0.33 , which were more moderate than estimates by Aguilar et al. (2009). More moderate genetic correlations indicate that genetics is not a limiting factor in Thailand because of lower production.

Correlations between permanent environmental effects with and without heat stress considered (Table 2 ) were also negative for all parities and ranged from -0.45 to -0.56 . They were similar to corresponding estimates by Aguilar et al. (2009). Thus, the cow response to heat stress is mostly environmental.

\section{CONCLUSIONS}

Holstein crosses can maintain production under high heat stress despite a lack of active management practices to alleviate such stress if the production level is low and the percentage of Holstein genetics is $<87 \%$. Any response to heat stress is mostly environmental and is strongly affected by parity.

\section{ACKNOWLEDGMENTS}

This study was financially supported by the Thailand Research Fund through the Royal Golden Jubilee PhD Program. The authors thank the Thai Department of Livestock Development (Pathumthani, Thailand) and private dairy farms for providing milk yield data and appreciate the assistance of Shogo Tsuruta and Ignacio Aguilar (both of the Department of Animal and Dairy Science, University of Georgia, Athens) and the editing expertise of Suzanne Hubbard (Animal Improvement Programs Laboratory, ARS, USDA, Beltsville, MD) and Jamie Williams (Department of Animal and Dairy Science, University of Georgia, Athens).

\section{REFERENCES}

Aguilar, I., I. Misztal, and S. Tsuruta. 2009. Genetic components of heat stress in dairy cattle with multiple lactations. J. Dairy Sci. 92:5702-5711.

Aguilar, I., I. Misztal, and S. Tsuruta. 2010. Short communication: Genetic trends of milk yield under heat stress for US Holsteins. J. Dairy Sci. 93:1754-1758.

Armstrong, D. V. 1994. Heat stress interaction with shade and cooling. J. Dairy Sci. 77:2044-2050.

Berman, A. 2008. Increasing heat stress relief produced by coupled coat wetting and forced ventilation. J. Dairy Sci. 91:4571-4578.

Bohmanova, J., I. Misztal, S. Tsuruta, H. D. Norman, and T. J. Lawlor. 2005. National genetic evaluation of milk yield for heat tolerance of United States Holsteins. Interbull Bull. 33:160-162.

Bohmanova, J., I. Misztal, S. Tsuruta, H. D. Norman, and T. J. Lawlor. 2008. Short communication: Genotype by environment interaction due to heat stress. J. Dairy Sci. 91:840-846.

Bryant, J. R., N. López-Villalobos, J. E. Pryce, C. W. Holmes, D. L. Johnson, and D. J. Garrick. 2007. Environmental sensitivity in New Zealand dairy cattle. J. Dairy Sci. 90:1538-1547.

Buaban, S. 2005. Dairy cattle improvement system in Thailand. Pages 1-8 in The experiences of dairy industry development in South East Asia, Hanoi, Vietnam.

Chanvijit, K., M. Duangjinda, V. Pattarajinda, and C. Reodecha. 2005. Model comparison for genetic evaluation of milk yield in crossbred Holsteins in the tropics. J. Appl. Genet. 46:387-393.

Freitas, M. S., I. Misztal, J. Bohmanova, and R. Torres. 2006a. Regional differences in heat stress in U.S. Holsteins. Commun. No. 01-11 in Proc. 8th World Congr. Genet. Appl. Livest. Prod., Belo Horizonte, Brazil.

Freitas, M. S., I. Misztal, J. Bohmanova, and J. West. 2006b. Utility of on- and off-farm weather records for studies in genetics of heat tolerance. Livest. Sci. 105:223-228.

Fuquay, J. W. 1981. Heat stress as it affects animal production. J. Anim. Sci. 52:164-174.

Madalena, F. E., R. L. Teodoro, A. M. Lemos, J. B. N. Monteiro, and R. T. Barbosa. 1990. Evaluation of strategies for crossbreeding of dairy cattle in Brazil. J. Dairy Sci. 73:1887-1901.

McDowell, R. E. 1985. Crossbreeding in tropical areas with emphasis on milk, health, and fitness. J. Dairy Sci. 68:2418-2435.

Misztal, I., S. Tsuruta, T. Strabel, B. Auvray, T. Druet, and D. H. Lee. 2002. BLUPF90 and related programs. Commun. No. 28-07 in Proc. 7th World Congr. Genet. Appl. Livest. Prod., Montpellier, France.

National Oceanic and Atmospheric Administration. 1976. Livestock hot weather stress. US Dept. Commerce, Natl. Weather Serv. Central Reg., Reg. Operations Manual Lett. C-31-76. US Govt. Printing Office, Washington, DC.

Ravagnolo, O., and I. Misztal. 2000. Genetic component of heat stress in dairy cattle, parameter estimation. J. Dairy Sci. 83:21262130 .

Ravagnolo, O., and I. Misztal. 2002. Effect of heat stress on nonreturn rate in Holsteins: Fixed-model analyses. J. Dairy Sci. 85:31013106 .

Ravagnolo, O., I. Misztal, and G. Hoogenboom. 2000. Genetic component of heat stress in dairy cattle, development of heat index function. J. Dairy Sci. 83:2120-2125.

Reodecha, C. 2002. Genetic evaluation of dairy cattle in Thailand Commun. No. 01-79 in Proc. 7th World Congr. Genet. Appl. Livest. Prod., Montpellier, France.

St-Pierre, N. R., B. Cobanov, and G. Schnitkey. 2003. Economic losses from heat stress by US livestock industries. J. Dairy Sci. 86(E. Suppl.):E52-E77.

West, J. W. 1999. Nutritional strategies for managing the heat-stressed dairy cow. J. Anim. Sci. 77(Suppl. 2):21-35.

West, J. W. 2003. Effects of heat-stress on production in dairy cattle. J. Dairy Sci. 86:2131-2144. 